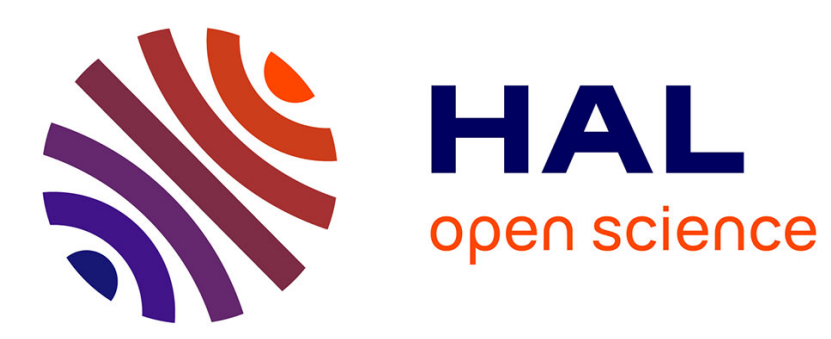

\title{
Multiphysic modelling of a microactuator based on the decomposition of an energetic material: application to microfluidics
}

\author{
Gustavo Aldolfo Ardila Rodriguez, Carole Rossi
}

\section{- To cite this version:}

Gustavo Aldolfo Ardila Rodriguez, Carole Rossi. Multiphysic modelling of a microactuator based on the decomposition of an energetic material: application to microfluidics. 2007. hal-00150263

\section{HAL Id: hal-00150263 \\ https://hal.science/hal-00150263}

Preprint submitted on 29 May 2007

HAL is a multi-disciplinary open access archive for the deposit and dissemination of scientific research documents, whether they are published or not. The documents may come from teaching and research institutions in France or abroad, or from public or private research centers.
L'archive ouverte pluridisciplinaire HAL, est destinée au dépôt et à la diffusion de documents scientifiques de niveau recherche, publiés ou non, émanant des établissements d'enseignement et de recherche français ou étrangers, des laboratoires publics ou privés. 


\title{
Multiphysic modelling of a microactuator based on the decomposition of an energetic material: application to microfluidics
}

\author{
Gustavo Adolfo Ardila Rodríguez, Carole Rossi \\ LAAS-CNRS, 7 avenue du colonel Roche, 31077 Toulouse Cedex 04, France
}

Email : gaardila@laas.fr

\begin{abstract}
We present the conception of a micro pressure source for microfluidics applications. It consists in 3 main parts: (i) a heating resistance built on a dielectric membrane, (ii) an energetic material which decomposes generating a high volume of biocompatible gas, (iii) an elastomer membrane with high elastic properties. PDMS is chosen as the membrane material for its elastic properties. A bimetallic energetic material composed of $\mathrm{Mn}$ and $\mathrm{Co}$ is chosen because of the high amount of biocompatible gas liberated from its decomposition [1].

When the actuation is required, the energetic material is heated beyond the ignition temperature to generate a high concentration of gas; the gain in pressure produces the deformation of the elastic membrane. Individual models have been developed for each physical phenomenon: (i) the heating of the resistance by an electro-thermal model, (ii) the gas generation from the decomposition of the energetic material based on an ideal gas model and a mass transfert model and coupled with the elastic membrane deformation with a mechanical deformation model. This paper presents each individual model under COMSOL Multiphysics that has been correlated with experimental results. Then, the implementation of all models into one global model allow us to predict the actuator performance as a function of input electrical signal.
\end{abstract}

\section{Introduction}

MEMS technologies in general and Microfluidics in particular are one of the most developed technologies in the last years. Further miniaturization and increase level of systems complexity are the current trend in Microsystems. In that context, new tools for the conception steps are essential to optimize the performance of the system, to save time and money during the development phase.

With the increased complexity level, multiphysics approaches taking into account the interactions between different physical phenomena, are necessary for the systems conception.

Some works have been recently reported on the multiphysics modeling of micro actuators [2-7]. This bibliography shows the difficulty in validating complete 3D models experimentally; often simplified models are validated either by analytical models or experimentally. Depending on the complexity of the structure or the multiphysic coupling, simplified models often leading to linearization of highly non-linear expressions are preferred.
In Microfluidics, an important issue is the integration of reliable, small and easy to use micro actuation parts for pumping and valving of liquids. Over the past decade a large variety of micro valves and pumps based on several effects including piezoelectric [8], electrostatic [9] and (thermo) pneumatic have been proposed $[10,11]$. These are often expensive and difficult in design and fabrication. In addition, their deflection is too small to pump or completely close a microfluidic channel necessary for a good valve. An exception is based on pneumatic actuation. However, these actuators are usually too large to be fabricated in a dense array format and to be fully integrated into the microfluidic lab-on-a chip [12]. An emerging concept is to integrate pressure sources directly in the microfluidic platform by integrating energetic materials on a micro heater fabricated into the microchannel [13]. When the actuation is required, the energetic material is heated up and generates a high volume of gas which therefore locally increases the pressure. The micro/nanoactuator based on these mechanisms can be fairly simply fabricated, low cost, very compact $\left(<1 \mathrm{~mm}^{2}\right)$, fast, biocompatible, integratable with different technologies (silicon, glass, plastics), adjustable and could be integrated on large scale.

The reliable integration in submillimeter scale, of, a microheater, a solid energetic material and an elastic membrane into a microchannel raises several modelling and technological challenges. The first one is to clearly understand the physics on which these actuators operate through multiphysics models, building up individual models for each physical phenomenon and then integrating them into a full package, enabling to make virtual prototyping. The second challenge is the elaboration of energetic materials that keeps mechanical actuation capabilities when it is deposited in a thin layer (thickness $<100 \mu \mathrm{m}$ ). The third one is to set up the MEMS technologies for the integration and interfacing of all materials (energetic, substrate, heater, polymeric membrane and fluid) at submillimeter scale.

In this paper we focus on the modelling issues. The first part of the paper is the presentation of individual multiphysics model built up using COMSOL Multiphysics. The numerical modelling issues will be discussed and compared with experimentation. In a second part, the integration of all individual models into a general model will be presented and multiphysics interfacing issues will be discussed.

\section{Description of the microactuator}


The proposed micro actuator made on silicon consists of 3 main parts as illustrated in Figure 2:

- One heating platform: it is made of one thin dielectric membrane $\left(\mathrm{SiO}_{2} / \mathrm{SiN}_{\mathrm{x}}\right)$ on which is deposited a polysilicon resistor [14].

- One elastic membrane which encapsulates energetic material: PDMS (PolyDiMéthylSiloxane) has been chosen for the demonstrator for its easy prototyping. [15]

- One energetic material [1]

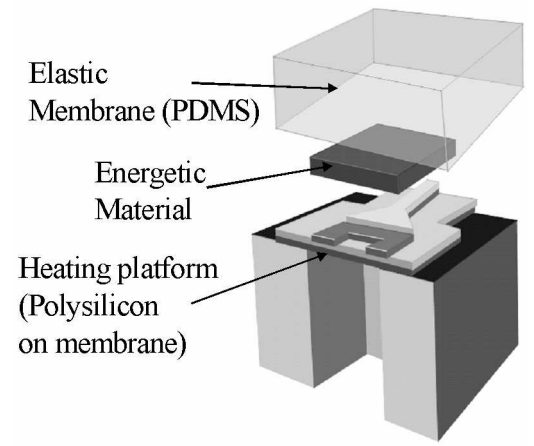

Figure 1. Micro actuator structure 3D view

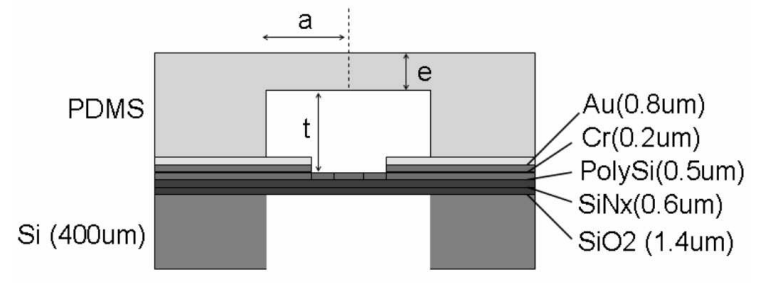

Figure 2. Micro actuator structure cut view characteristics

The micro heater and membrane structures are shown in Figure 2 and Figure 3. The geometrical parameters taken for the simulation are given in the Table $1 .$.

(a)

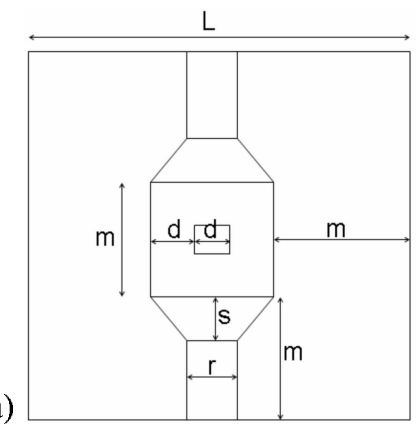

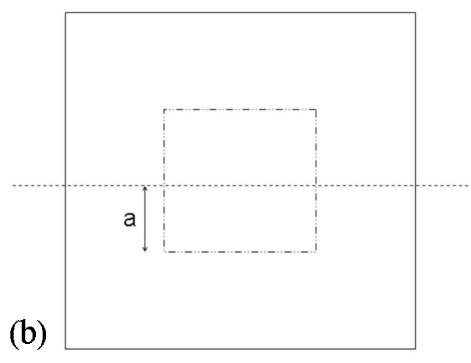

Figure 3. Membrane (a) and heater geometrical (b) characteristics.

Table 1. Micro actuator geometrical parameters.

\begin{tabular}{|c|c|}
\hline Geometrical parameter & Value $(\boldsymbol{\mu m})$ \\
\hline$L$ & 500 \\
\hline$m$ & 166 \\
\hline$r$ & 92 \\
\hline$d$ & 55 \\
\hline$s$ & 72 \\
\hline$a$ & 250 \\
\hline$e$ & 30 \\
\hline$t$ & 100 \\
\hline
\end{tabular}

When the actuation is required, a current flows in the polysilicon resistor heating up by the Joule effect the polysilicon and by thermal conduction the energetic material in contact with the heater. When the ignition temperature of the energetic material is reached, a high volume of air is released. Then, the pressure in the cavity increases and deforms the elastic membrane.

3 models describe the microactuation:

- the electro-thermal model to simulate the heating by Joule effect,

- the gas generation from the decomposition of the energetic material, once the ignition temperature $\left(250^{\circ} \mathrm{C}\right)$ [1] is reached,

- a mechanical model to predict the membrane deformation as a function of gas pressure.

\section{Mathematical models}

\subsection{Electro thermal model}

The electro-thermal model includes the well known heat flow equation and the electric potential equation. The link between the two equations is done by the Joule effect $\left(Q=\sigma\left|\nabla V_{e}\right|^{2}\right)$

\section{Electric potential}

Heat flow

$$
-\nabla \cdot\left(\sigma \nabla V_{e}\right)=0
$$

$$
\rho \cdot C_{p} \frac{\partial T}{\partial t}-\nabla .(k \nabla T)=Q
$$

\subsection{Gas evolution model}

The evolution of the enclosed gas in the cavity follows the Fick's law of diffusion for the concentration of species $(c)$ : [16] 


$$
\frac{\partial c}{\partial t}-\nabla \cdot(D \nabla c)=R
$$

Where $D$ is the diffusion coefficient and $R$ the reaction term. In this approach no convection is considered. The pressure in the cavity could be directly related to the gas concentration. Considering the gas as ideal we obtain:

$$
P=c M T
$$

where $M$ is the air molar mass

\subsection{Membrane deformation model}

The classical mechanical model is based on the small deformation approximation: the membrane deformationto-thickness ration is very small $(w / e<<1)$ and the membrane deformation-to-lateral dimension $(w / 2 a<<1)$ is low [17]. In our case, both assumption are not true ( $w / e \sim 3-5$ and $w / 2 a \sim 0.2-0.4$ ), therefore, the PDMS membrane deformation is simulated using a large deformation model.

The strain tensor is expressed as follow [17]:

$$
\varepsilon_{i j}=\frac{1}{2}\left(\frac{\partial u_{i}}{\partial x_{j}}+\frac{\partial u_{j}}{\partial x_{i}}+\frac{\partial u_{k}}{\partial x_{i}} \cdot \frac{\partial u_{k}}{\partial x_{j}}\right)
$$

where $u$ represents the deformation in a given direction, $x$ is the spatial coordinate and the sub indices $i, j, k$ represent each component in $x, y, z$ direction. The non-linear term $\partial u_{k} / \partial x_{i} . \partial u_{k} / \partial x_{j}$ characterizes the large deformation behavior.

The membrane stress can be calculated from the First Piola-Kirchhoff stress $p$ 18] as:

$$
p=\frac{\partial W h y p}{\partial \nabla \vec{u}}
$$

where $\nabla \vec{u}$ is the displacement gradient and Whyp is a strain energy function which characterizes the hyper elastic properties of the PDMS.

The Neo-Hookean Model proposed by COMSOL Multi-physics [19] considers the strain energy function as follow:

$$
W h y p=\frac{1}{2} \mu\left(I_{1}^{\prime}-3\right)+\frac{1}{2} \kappa\left(J_{e l}-1\right)^{2}
$$

where $\mu$ and $\kappa$ are the shear and bulk modulus of the PDMS, respectively. $J_{e l}$ is the elastic part of the total volume change of the PDMS:

$$
J_{e l}=\frac{J}{J_{t h}}=\frac{J}{\left(1+\varepsilon_{t h}\right)^{3}}
$$

Here, $J$ represents the ratio between the current volume and the original volume and $J_{t h}$ is the thermal expansion expressed in terms of the thermal strain $\varepsilon_{t h}$.

$I_{1}^{\prime}$ is the first modified strain invariant $: I_{1}^{\prime}=\left(C_{11}+C_{22}+C_{33}\right) J_{e l}^{-\frac{2}{3}}$ where $C_{11}, C_{22}$ and $C_{33}$ are the matrix components of the Cauchy-Green tensor $C=F^{T} F$, where $F$ is the deformation gradient matrix containing information about deformation and rotation.

\section{Model implementation}

The equations (1-4) and (5-8) have been solved numerically using the Finite Element Method (FEM). Several material properties are required to solve the different mathematical equations presented in the section 2:

- The electrical conductivity $(\sigma)$, thermal conductivity $(k)$ and the volumic mass $(\rho)$ of all the structural materials and air: see Table 2 .

- The Young modulus $(E)$, the Poisson coefficient (v) and the residual stress $\left(\sigma_{o}\right)$ of the PDMS

- The air characteristics: volumic mass $\left(\rho_{\text {air }}\right)$ and molar mass $(M)$ depend on $P, T$ and initial volume, respectively.

Table 2. Properties of the materials used for the fabrication of the micro actuator.

\begin{tabular}{|c|r|r|r|r|}
\hline Material & $\begin{array}{c}\sigma \\
(\mathbf{S} / \mathbf{m})\end{array}$ & $\begin{array}{c}\mathbf{k} \\
(\mathbf{W} / \mathbf{m} \cdot \mathbf{K})\end{array}$ & $\begin{array}{c}\rho \\
\left(\mathbf{k g} / \mathbf{m}^{\mathbf{3}}\right)\end{array}$ & $\begin{array}{c}C p \\
(\boldsymbol{J} / \mathbf{K g} . \mathbf{K})\end{array}$ \\
\hline Silicon & Not used & 100 & 2328 & 702 \\
\hline SiO2 & Not used & 1.4 & 2270 & 1000 \\
\hline SiNx & Not used & 49 & 2270 & 1000 \\
\hline $\begin{array}{c}\text { Polysilicon } \\
\text { (Bore } \\
\text { implanted })\end{array}$ & $\begin{array}{r}\sigma_{\text {poly }}(T) \\
5146.3 \\
\left(23^{\circ} \mathrm{C}\right)\end{array}$ & 100 & 2328 & 700 \\
\hline Gold & $4.4 \times 10^{7}$ & 297 & 19300 & 128.7 \\
\hline Chromium & $7.3 \times 10^{6}$ & 93.7 & 7150 & 449 \\
\hline PDMS & Not used & 0.15 & 965 & 1200 \\
\hline Air & Not used & $k_{\text {air }}(T)$ & $\rho_{\text {air }}(T)$ & $C p_{\text {air }}(T)$ \\
\hline
\end{tabular}

\subsection{Thermal properties of the gas produced by the energetic material}

As discused in section 4.1 (equation 9) the gas liberated by the energetic material is composed of $\mathrm{N}_{2}, \mathrm{O}_{2}$ and $\mathrm{H}_{2} \mathrm{O}$ vapor, they are present in the air but not in the same proportion. Nevertheless as a first approach in the gas generation from the energetic material, we consider the gas generated as air.

The Nusselt $(\mathrm{Nu})$ number has been used to determine the convection coefficient $(h)$, given by:

$$
\begin{gathered}
h=N u \frac{t}{2 a} \\
N u=A(G r \cdot \operatorname{Pr})^{n}\left(\frac{t}{2 a}\right)^{m}
\end{gathered}
$$

Where $A, n$ and $m$ are constant depending on the value of the product $G r \times P r$. The Grashof $(G r)$ and Prandtl $(P r)$ numbers of air contained in the micro cavity are written as follows :

$$
G r=\frac{g \cdot \beta_{\text {air }}\left(T_{\max }-T\right) t^{3} \rho_{\text {air }}{ }^{2}}{\mu_{\text {air }}{ }^{2}}
$$

Where $g$ is the gravity with a value of $9.8 \mathrm{~m} / \mathrm{s}^{2}, \beta_{\text {air }}$, $\rho_{a i r}, \quad \mu_{a i r}$ are the air expansion coefficient, density, dynamic viscosity respectively.

They are temperature dependant and the values can be found at atmospheric pressure in the literature [16]. 
The air is contained in a square cavity. Its lateral dimension is $2 a$ and height is $t$ (see Figure 2 and ). We calculate the Grashof number for the highest conditions in pressure and temperature in the cavity as function of time, when the maximal electrical power studied is applied $(100 \mathrm{~mW})$. We obtained a peak of pressure of $P=466.7 \mathrm{MPa}$ and a temperature at the heating platform $\left(T_{\text {max }}\right)$ of $342^{\circ} \mathrm{C}$, the Grashof number is equal to 606 and the air Prandtl number is equal to 0.7 [16]

$G r \times P r=424.2<<1700$ that is the limit of the conduction regime [16]. Therefore the air contained in the cavity is in a purely conduction regime and convection coefficient is set to 0 .

\subsection{Gas diffusion}

The diffusion coeffcient can be calculated as function of the nature of the gas, the pressure and the temperature in the cavity as: [16]

$$
D=435.7 \frac{T^{3 / 2}}{p\left(V_{A}^{1 / 3}+V_{B}^{1 / 3}\right)^{2}} \sqrt{\frac{1}{M_{A}}+\frac{1}{M_{B}}}
$$

$V$ indicating the molecular volume of the constituents $A$ and $B$ and $M$ as the molecular weight, for the air $V=29.9$ and $M=28.9$. In our model the diffusion coefficitent can not be considered constant as the temperature and the pressure in the cavity changes in time and are not homogeneus in space.

\subsection{Meshing optimization}

The electro-thermal, membrane deformation and gas generation models are implemented under COMSOL Multiphysics. The optimized meshing for the simulation is determined by performing an independent grid study to minimize the modeling error. When the change in the solution between subsequent stages of meshing refinement is considered to be negligible, the lower, but still sufficient, mesh resolution is kept. Figure 4 illustrates the procedure for the heating platform: the polysilicon microheater maximum temperature and time of simulation is compared among different stages of meshing refinement: the compromise between simulation time and accuracy is reached for the rounded point and gives the good optimal meshing.

For the heater platform, the optimized mesh consists of 7707 tetrahedral and prism elements on one quarter of the microheater structure. Figure 5 shows the meshing of the heater platform separated in the substrate and the dielectric membrane.

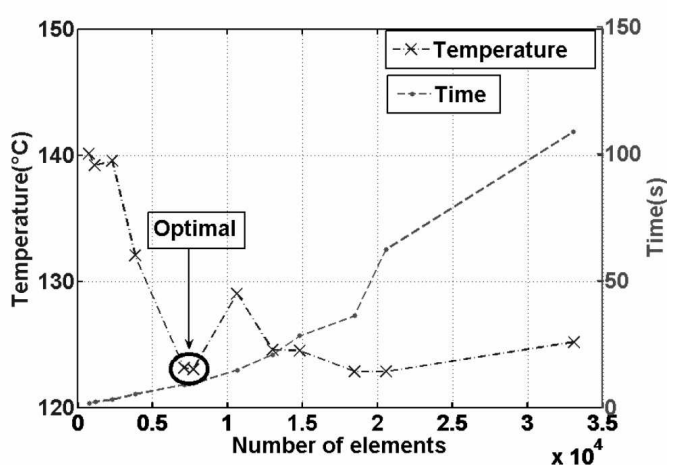

Figure 4. Example of mesh optimization procedure for the heating platform model

(a)

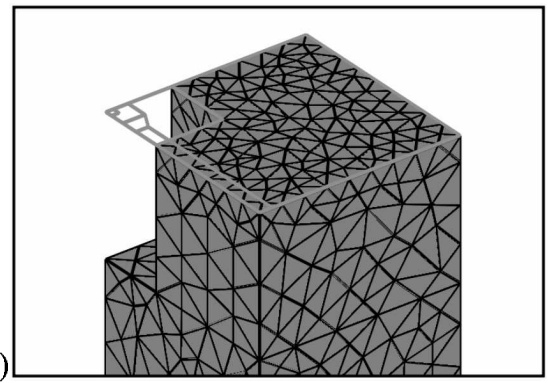

(b)

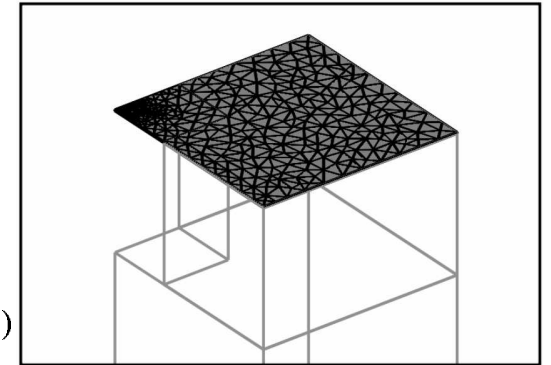

Figure 5. Heating platform. Substrate (a) and dielectric membrane (b) meshing

The optimized meshing for the PDMS membrane contains 5104 tetrahedral elements (see Figure 6).

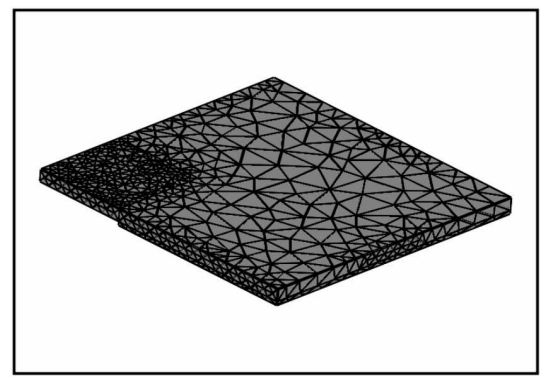

Figure 6. Meshing of the elastic membrane

The optimized meshing for the $2 \mathrm{D}$ axisymetric gas generation model contains 12103 triangular elements (see Figure 7).

\section{Individual model implementation and experimental validation}




\subsection{Heating platform}

The results for the microheater simulation are illustrated in Figure 8. Here the temperature of the heater dielectric membrane is given at the steady state and for the following conditions: Applied Voltage: 4V; electrical power: $29.8 \mathrm{~mW}$; convection coeffcient $\mathrm{h}=0$.

From the simulation, the required power and the resulting equivalent temperature distribution are obtained.

The graph of Figure 9 gives the heater maximal temperature as a function of the electrical power with and without taking into account the temperature effect on $\sigma_{\text {poty }}$. A comparison with Infrared (IR) thermal characterization, made with a CEDIP JADE III MW camera, enables to evaluate the modeling error. From this graph, below a maximal temperature of $116^{\circ} \mathrm{C}$ the maximal error in the measurement is $33 \%$, above this temperature the maximal error reduces to $16 \%$. The difference between the model and the measurements could be explained by the uncertainty to evaluate the value of the emissivity coefficient $(\varepsilon)$ of the different materials using the IR measurement.

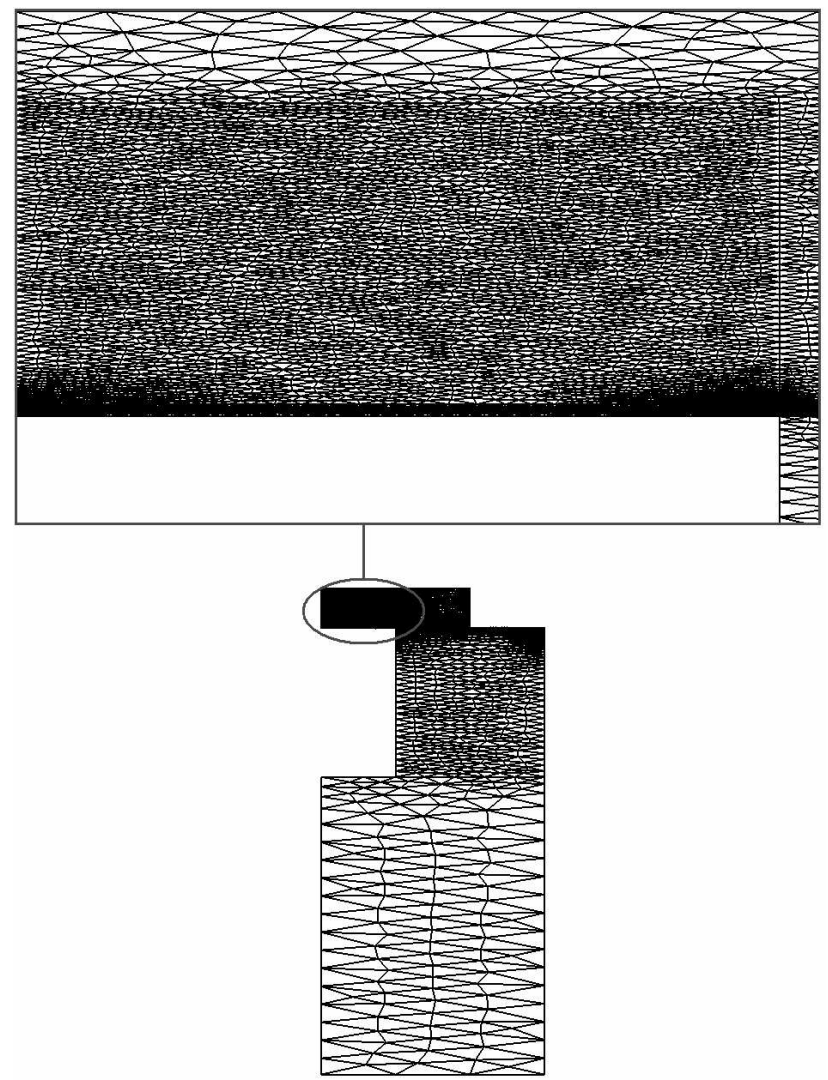

Figure 7. Meshing of the 2D axisymmetric model for the gas generation including the electro-thermal model

\subsection{Membrane deformation}

The results for the elastic membrane deformation simulation are illustrated in Figure 10. Here the deformation $(w)$ of the PDMS membrane with parameters $E=4 \mathrm{MPa} ; v=0.48 ; \sigma_{o}=0$ is given at the steady state and for the following conditions: Applied pressure: 0.01MPa; boundary: clamped all around the membrane.

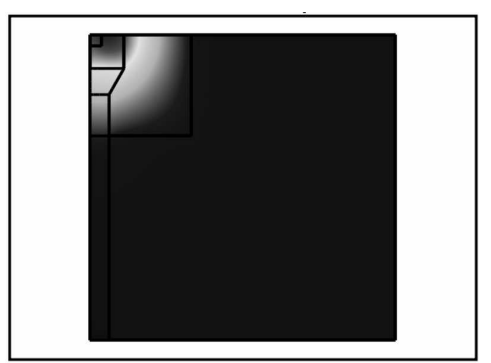

Figure 8. Example of temperature distribution for a $500 \mu \mathrm{m} \times 500 \mu \mathrm{m}$ dielectric membrane heating platform.

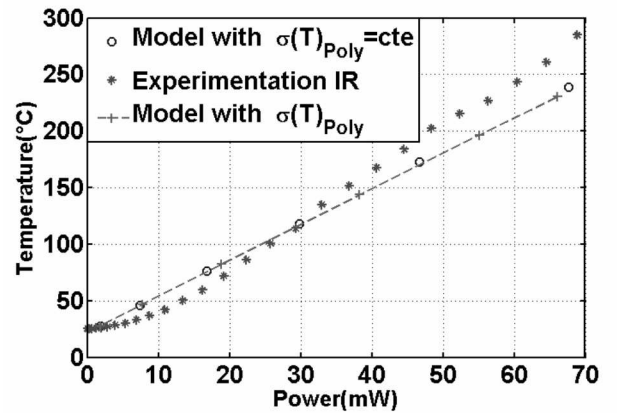

Figure 9. Heater maximal temperature vs. electrical power

Figure 11 gives the theoretical and experimental maximum membrane deformation as a function of the pressure inside the cavity. The curves correspond to a $30 \mu \mathrm{m}$ thick PDMS membrane fabricated at LAAS and having a Young Modulus of $4 \mathrm{MPa}$ measured by the "Bulge test" [20] and nanoindentation [21]. The comparison shows a difference in the non-linearity of the curves, experimental curves are almost linear because of the separation effect of the membrane from the substrate as pressure increases.

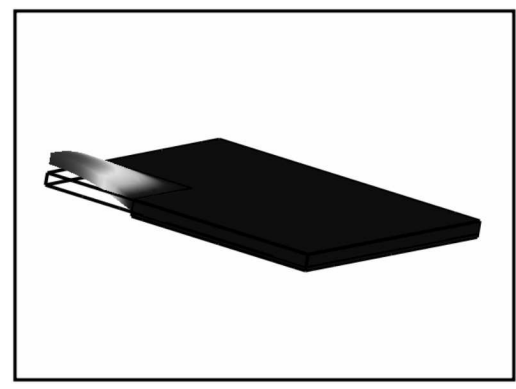

Figure 10. Membrane deformation for a $500 \mu \mathrm{m} \times 500 \mu \mathrm{m}$ membrane being $30 \mu \mathrm{m}$ thick.

\subsection{The gas generation and its evolution}

As a first approach in the implementation of the model describing the gas generation, some simplifations were made:

- A 2D axisymmetric model is implemented to validate the concept before implementing a full $3 \mathrm{D}$ model, 


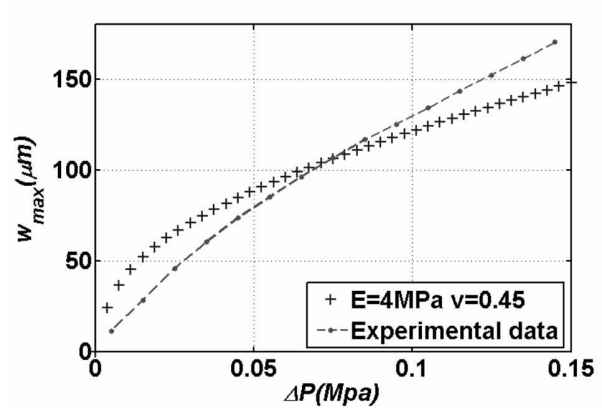

Figure 11. Comparison between experimental and simulated results for the deformation of a $500 \mu \mathrm{mx} 500 \mu \mathrm{m}$ membrane.

- As the geometry of the heating resistance is different from the $3 \mathrm{D}$ model, a calibration of the $2 \mathrm{D}$ model in terms of applied tension and obtained heating temperature was made by modifying the electrical conductivity of the heating material,

- The amount of energetic material deposited on the heating platform is calculated from the profilometer measurement (see section 4.2), the mean thickness of the deposited material is $1.4 \mu \mathrm{m}$. We use this value to consider an uniform desposit of the material,

- The gas liberated from the energetic material is composed of more than one species (see section 4.2), in this first approach the gas is considered as air, even if the proportion of the individual species are not exacly the same,

- The gas generation is considered to happen instantly once the ignition temperature is reached, in that way the simulation is made in two times: First; an stationary simulation considering the energetic material deposited over the heating platform. In this simulation the temperature distribution is obtained for a given applied voltage, in this case $6.3 \mathrm{~V}$. Then, the assessment of the quantity of material that reaches the ignition temperature is made as shown in Figure 12. This is taken as the initial condition for the next step; Secondly, once the quantity of the material that decomposes in gas is known, the transient simulation of the gas evolution can be calculated as a function of the electrical applied power. The observation point where the transient measurements where made is shown in Figure 12.

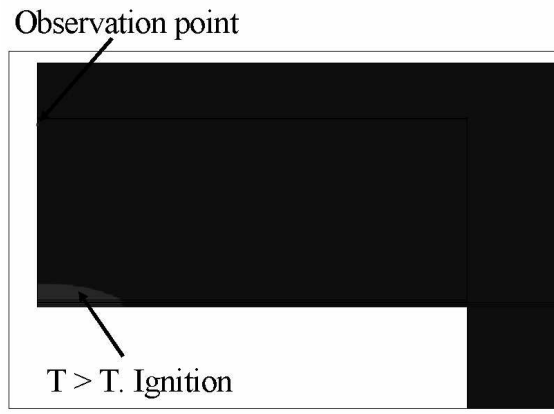

Figure 12. Stationary electro-thermal simulation. Evaluation of the energetic material with a temperature higher than the ignition temperature. Observation point for the transient simulation
Figure 13 shows the fast concentration evolution ( $2 \mathrm{~ms}$ ) compared to the thermal evolution of the system, starting from the initial air concentration $\left(41.44 \mathrm{~mol} / \mathrm{m}^{3}\right)$ calculated at ambient temperature and atmospheric pressure to the final concentration of the cavity (51.34 $\left.\mathrm{mol} / \mathrm{m}^{3}\right)$.

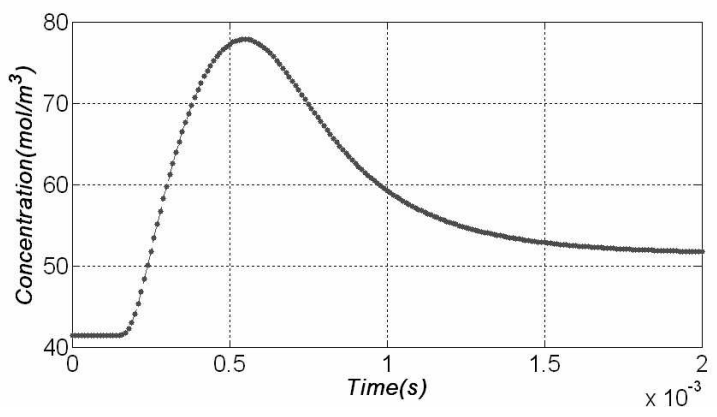

Figure 13. Gas concentration evolution on the observation point near the PDMS membrane

Figure 14 shows the evolution of the temperature in the cavity as the actuator is turned off, it takes $3.6 \mathrm{~s}$ to reach the stationary state at ambient temperature.

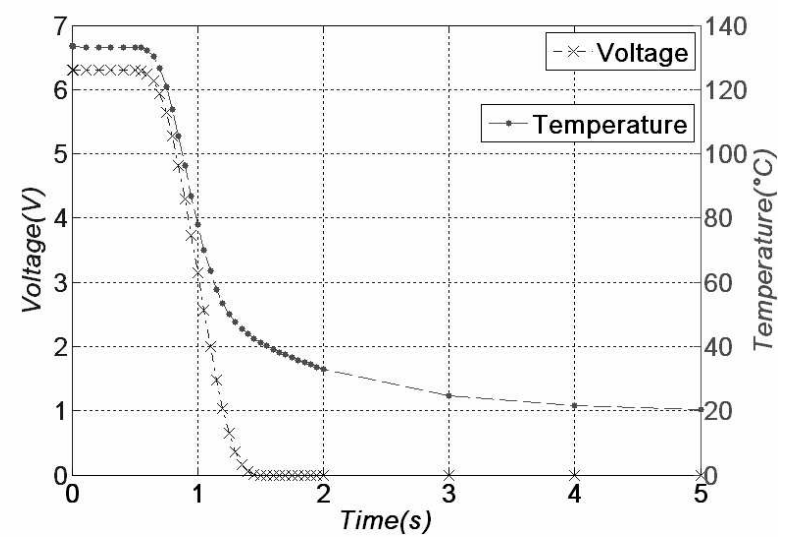

Figure 14. Temperature evolution on the observation point under the PDMS membrane

Figure 15 shows the evolution of the pressure in the cavity as the actuator is turned off. After $1 \mathrm{~ms}$ from the decomposition of the gas, a high peak of pressure is detected (see the zoom in Figure 15). The assessment of the effect of this pressure peak on the global performance of the system is under study. A first stationary state is reached at $0.073 \mathrm{MPa}$ once the actuator is still on, then the pressure follows the temperature evolution in the cavity, reaching the final pressure $0.025 \mathrm{MPa}$. 


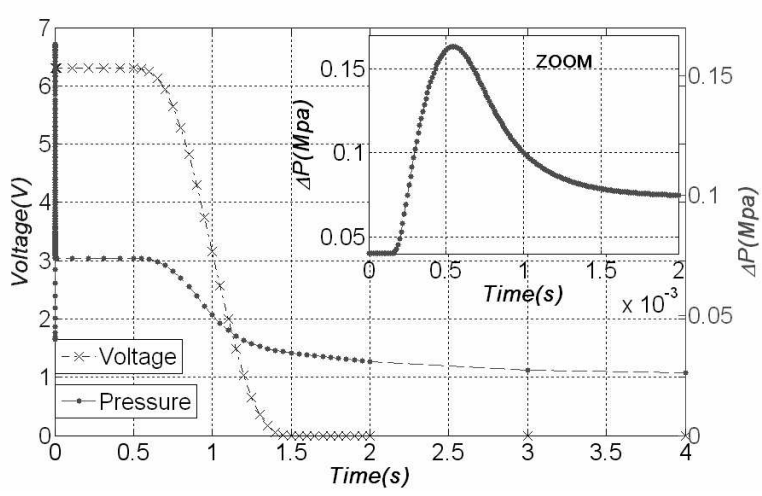

Figure 15. Pressure evolution on the observation point under the PDMS membrane

\section{Global model assessment}

The goal of the final system model is to predict the amplitude of the actuation as a function of the input signal, that is, the maximal deformation of the membrane as a function of the electrical applied power $\left(w_{\max }=\mathrm{f}(I \times V e)\right)$.

From the axisymmetric model, a pressure is obtained as a function of the applied power, Figure 16 shows that the minimal electrical power required to obtain the actuation is $68.7 \mathrm{~mW}$. From this pressure data, we can obtain the deformation of the hyperelastic membrane with the 3D model (see section 5.2).

Figure 16 gives also the maximal deformation of the elastic membrane as function of the electrical power.

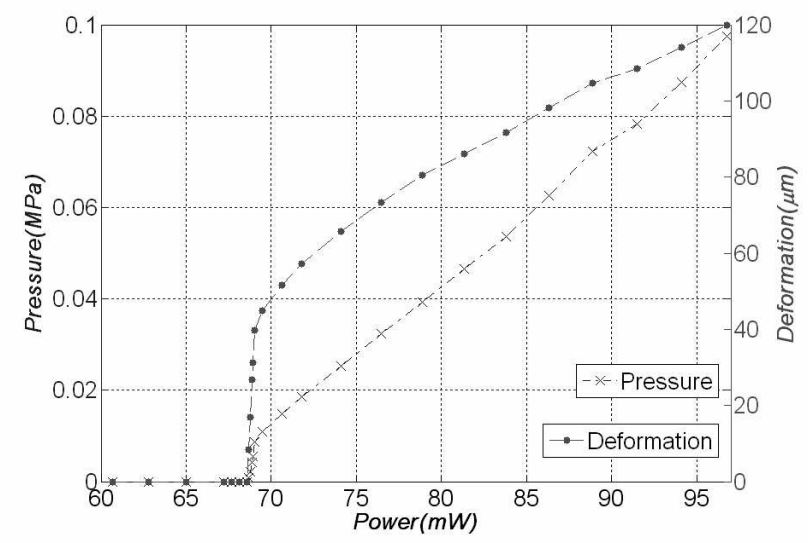

Figure 16. Global model assessment in stationary state. Cavity pressure and maximal deformation of the elastic membrane as a function of the applied electrical power

\section{Conclusions}

In this article we have presented a micro pressure source based on the decomposition of an energetic material to illustrate a multiphysics conception approach based on the COMSOL Multiphysics software.

In this actuator, an electrical power of $86.3 \mathrm{~mW}$ is applied to the heating platform to obtain a membrane maximal deformation of $100 \mu \mathrm{m}$.

First an electro-thermal model of a heating platform has been implemented and validated by IR measurements.
Simulations results on the micro balloon blowing show a reasonable agreement with experimental data. Still, some discrepancies are found in the non-linearity of the curves. Possible modifications on the model should be considered. At the same time, technical aspects, as the adherence between the substrate and the elastic membrane will be optimized in order to characterize the membrane properties and increase the system's performance.

A first approach of a model for the gas generation from the decomposition of the energetic material is presented, results show quite fast transient behavior in the gas concentration dynamics inducing a fast peak in the cavity pressure, a dynamic evaluation of the membrane response to this peak must be considered, this will lead us to a full multiphysics coupling with the membrane deformation as a fluid-structure interaction.

The advantage in actuating with an energetic material is exposed as the efficiency in the level of actuation increases reducing the electrical power needs. The reduced power consumption of this actuator makes it quite appropiated for microfluidic portable applications or applications where nowadays high integrated pressure sources are required [22].

Next a global multiphysics model including the interaction of the acturator with the actuated fluid in a microchanel is envisaged.

\section{Acknowledgments}

This research is fully supported by a French National Research Agency ANR grant. The authors gratefully acknowledge the services TEAM and 2I from the LAASCNRS for their competences and skills that made possible this work. The authors also would like to thank B. Chaudret, S. Sabo-Etienne and P. fau from the LCC CNRS and A. F. Mingotaud, M. Mauzac and J. Fitremann from the IMRCP for their colaboration in the project. The authors also wish to thank the COMSOL support team for their services.

\section{References}

1. C. Pradère, S. Suhard, L. Vendier, G. Jacob, B. Chaudret, S. Sabo-Etienne, to be published.

2. Cabal, A. et al, "Thermal actuator with optimized heater for liquid drop ejectors", Sensors and Actuators $A$ Vol. 123-124 (2005) pp. 531-539.

3. Harouche, I. P. F. and Shafai, C. "Simulation of shaped comb drive as a stepped actuator for microtweezers application", Sensors and Actuators A, Vol. 123-124 (2005), pp. 540-546.

4. Park, Y. H. and Park, K. C. "High-fidelity modeling of MEMS resonators-Part II: Coupled beamsubstrate dynamics and validation", J. Micromech. Syst. Vol. 13 (2).

5. Pandiyan, J. et al, "Modelling \& simulation of novel three arm MEMS actuators \& its application", International MEMS Conference 2006, Journal of Physics: Conference Series, Vol. 34 (2006), pp. 436441. 
6. Zhu, Y. et al, "A thermal actuator for nanoscale in situ microscopy testing: design and characterization", $J$. Micromech. Microeng. Vol. 16 (2006), pp. 242-253.

7. Atre, A. "Analysis of out-of-plane thermal microactuators" J. Micromech. Microeng. Vol. 16 (2006), pp. 205-213.

8. Truong, Thai-Quang and Nguyen, Nam-Trung, "A polymeric piezoelectric micropump based on lamination technology", J. Micromech. Microeng. Vol. 14 (2004), pp. 632-638.

9. Bourouina, T. et al, "Design and simulation of an electrostatic micropump for drug-delivery applications", J. Micromech. Microeng. Vol. 7 (1997), pp. 186-188.

10. Baek, J. et al, "A pneumatically controllable flexible and polymeric microfluidic valve fabricated via in situ development", J. Micromech. Microeng., Vol. 15 (2005), pp. 1015-1020.

11. Chien-Chong, H. et al, "An on-chip air-bursting detonator for driving fluids on disposable lab-on-achip systems", J. Micromech. Microeng. Vol. 17 (2007) 410-417.

12. Song, W. H. and Lichtenberg, J., "Thermo-pneumatic, single-stroke micropump », J. Micromech. Microeng., Vol. 15 (2005), pp. 1425-1432.

13. Rossi, C. and Estève, D., "Micropyrotechnics, a new technology for making energetic microsystems: review and prospective", Sensors and Actuators A, Vol. 120 (2005), pp. 297-310.

14. Rossi, C. et al, "Realization and performance of thin $\mathrm{SiO} 2 / \mathrm{SiNx}$ membrane for micro-heater applications", Sensors and Actuators A Vol. 64 (1998), pp. 241-245.

15. Armani, D. K. et al, "Re-configurable fluid circuits by PDMS elastomer micromachining", 12th Int. Conf. on MEMS (MEMS 99) (Orlando, FL) pp. 222-227.

16. Holman, J. P., Heat Transfer, Mc Graw Hill (1997)

17. Timoshenko, S. P. and Woinowsky-Krieger, S., Théorie des plaques et coques, Béranger (Paris, 1961).

18. Tadmor, E. B. et al, "Mixed finite element and atomistic formulation for complex crystals", Phys. Rev. B, Vol. 59, No. 1 (1999), pp. 235-245.

19. Hoel, A. and Jullien, M. C., "Modelisation of a hyperelastic polymer membrane deformation", COMSOL Multiphysics Conference 2005, (Paris), pp. 37-39.

20. Poilane, C. et al, "Analysis of the mechanical behaviour of shape memory polymer membranes by nanoindentation, bulging and point membrane deflection tests", Thin Solids Film Vol. 379 (2000), pp.156-165.

21. Zhang, W. et al, "Novel room-temperature first-level packaging process for microscale devices", Sensors and Actuators $A$ Vol. 123-124 (2005), pp. 646-654.

22. Thorsen, T. et al, "Microfluidic large-scale integration", Science, Vol 298 (2002), pp 580. 